\title{
Triggering mechanisms of soil instability
}

\author{
A. Daouadji ${ }^{1}, \mathrm{H} . \mathrm{Al} \mathrm{Gali}^{1}$ \& F. Darve ${ }^{2}$ \\ ${ }^{1}$ Laboratoire de Physique et Mécanique des Matériaux, \\ UMR CNRS 7554, Université Paul Verlaine, Metz, France \\ ${ }^{2}$ Laboratoire Sols, Solides, Structures RNVO, Alert Geomaterials, \\ Institut National Polytechnique de Grenoble, UJF, CNRS, France
}

\begin{abstract}
In this study, we present a device designed to investigate the behavior of very loose sand subjected to strain and stress loading paths. The influence of these loading paths is analyzed with particular attention to potential instabilities. Comparisons are made with results obtained from experimental data from literature. A particular stress path, i.e. a constant shear undrained path, is then detailed and results are discussed. Experimental results show that diffuse mode failure occurs before the Mohr-Coulomb failure surface is reached. It is shown for these undrained tests that excess pore pressure results from collapse and it is not a trigger parameter.

Keywords: instability, collapse, very loose sand, constant shear undrained path, diffuse failure, load-controlled triaxial tests.
\end{abstract}

\section{Introduction}

Several studies have shown that a plastic limit criterion, such the Mohr-Coulomb criterion, does not explain all the types of ruptures that occur in soils. Previous studies well explain the localization phenomena that can occur during the loading. Failure is often the result of strain localization (vanishing determinant of the acoustic tensor as criterion, for example) which is close to, but does not reach, the Mohr-Coulomb criterion. However, in case of very loose sands, recent studies (Servant et al. [15]) have shown that failure can develop in a diffuse mode and in this case the observed failure mode is a diffuse collapse. Diffuse mode implies that criterion for bifurcation are reached before the localization criterion. It is important to note that these collapses strictly occur inside Mohr-Coulomb plastic limit criterion and that the conventional failure analysis cannot explain them. Indeed, some 
theoretical results have explained the occurrence of landslides on gently slopes (approximately $15 \mathrm{deg}$ ) ([2], [11], [3], [15]).

The purpose of this paper therefore is to give a response concerning the mode of deformation after bifurcation. This work proposes a new test which follows a particular path: constant shear stress undrained test (C.S.U.). In order to check if excess pore pressure is the consequence of collapse like as was shown by Eckersley [7] and Skopek et al. [14] for drained tests. In other words, if excess pore pressure is a trigger parameter in undrained conditions. Finally this test examines the response of a material when a disturbance occurs during an undrained test under constant shear stress loading conditions (trigger factor).

\section{Experimental setup}

This section presents the experimental apparatus developed to impose a constant shear stress on the soil specimen. This particular loading path (detailed in section 4) is applied in undrained conditions unlike in previous experimental studies presented by Skopek et al. [14] on dry sand and by di Prisco and Imposimato[5] and Gajo [8] on drained saturated sands. First, the components of the entire experimental setup will be presented, then the testing procedure and the characteristics of the sand used will described

\subsection{Testing apparatus}

Axial displacement is imposed by a Whykeham Farrance $\mathrm{R}$ ) Tritech (100 KN) displacement-controlled apparatus. The displacement rate is chosen by selecting a velocity in the range of 0.00001 to $5.99999 \mathrm{~mm} / \mathrm{mn}$. However, the loading can be completely applied via a piston which can be assembled on the Tritech. With this piston arrangement mixed loading (i. e. displacement-controlled then loadcontrolled) can be applied. Two GDS@ digital pressure / volume controllers are used to perform isotropic consolidated drained tests. Back pressure is measured with a Wykeham Farrance $\mathbb{B} 17060$ pressure transducer. During testing, the measured value is compared to the applied pressure. Axial displacement is measured by an external LVDT and changes in volume are measured by the piston displacement into and out of the GDS controller. The forces are measured by an internal submersible load cell with the capacity of 1 or $5 \mathrm{KN}$ depending of the initial density and the effective mean pressure. All tests variables are stored in a microcomputer.

\subsection{Sample preparation}

\subsubsection{Specimen preparation}

The moist tamping (MT) method is used to prepare the specimen of two nominal dimensions $d_{1}=50 \mathrm{~mm}$ diameter and $h_{1}=50 \mathrm{~mm}$ height and $d_{2}=105 \mathrm{~mm}$ diameter and $h_{2}=70 \mathrm{~mm}$ height. The sand has a moisture content of about $3-4 \%$ in order to reach near maximal void ratio before and after isotropic consolidation of about the maximum void ratio $\left(e_{\max } \approx 1\right.$, see table 1$)$.In order to obtained 
homogeneous samples, sand was carefully placed in five layers in the mould (Chu and Leong [1]). The membrane is sealed at the base of the cell and at a top cap. Saturated porous stones are placed in enlarged end plates to minimize friction and to allow homogeneous deformations at large strains. A small vacuum (10 KPa) is applied to permit the removal of the split mould. The cell is then put into the testing apparatus and filled with water. A small confining pressure $(20 \mathrm{KPa})$ is then applied and reached a value of $30 \mathrm{KPa}$ when the vacuum is nil.

\subsubsection{Saturation and isotropic consolidation}

A de-aerated water percolation is carried out to ensure sample saturation. Both cell pressure and back pressure are increased simultaneously in steps of $30 \mathrm{KPa}$. During this process the B-Skempton coefficient is checked and samples are assumed to be saturated if $B \geq 96 \%$. In order to study the instability domain for a given void ratio and to compare our results with those of others studies, three effective mean pressures are used: $p_{o}^{\prime}=100,300$ and $750 \mathrm{KPa}$.

\subsubsection{Void ratios}

By drying the sample, the final void ratio is calculated. This void ratio is the same as the void ratio after consolidation $e_{c}$ (as the test is undrained). The void ratio before consolidation $\left(e_{o}\right)$ is obtained from the measured volume variation during isotropic consolidation and by assuming that grains and water are incompressible. Comparison of the initial void ratio $e_{i}$ (accounting for the membrane thickness) and $e_{o}$ shows that $e_{i}$ is slightly higher than $e_{o}$ due to strain that occur during the saturation phase and also during consolidation (see table 1).

Table 1: Characteristics of the undrained triaxial tests on Hostun sand S28.

\begin{tabular}{c|c|c|c|c|c|c}
\hline Test \# & $p_{0}^{\prime}[\mathrm{KPa}]$ & $e_{i}$ & $e_{o}$ & $e_{c}$ & $\phi_{m o b}\left[^{\circ}\right]$ & $q / p_{0}^{\prime}$ \\
\hline 6 & 100 & 1.159 & 1.086 & 0.974 & 15.26 & - \\
\hline 42 & 300 & 1.140 & 1.060 & 1.025 & 15.67 & - \\
\hline 7 & 750 & 1.196 & 1.083 & 1.000 & 14.89 & - \\
\hline 31 & 100 & 1.180 & 1.136 & 1.085 & 12.60 & 0.285 \\
\hline 26 & 300 & 1.147 & 1.070 & 0.996 & 12.45 & 0.218 \\
\hline 41 & 300 & 1.132 & 1.101 & 1.026 & 13.07 & 0.305 \\
\hline 27 & 750 & 1.154 & 1.136 & 1.005 & 12.87 & 0.210 \\
\hline
\end{tabular}

\subsection{Sand used for testing}

The sand used for this study is a Hostun S28 sand. The quartzic grains are subangular and the grain size distribution is uniform. The principal characteristics are 
summarized in table 1 . The grain size distribution is given by the Fig. 1.

Table 2: Basic properties of Hostun S28 sand.

\begin{tabular}{c|c|c|c|c|c|c}
\hline Type & $\begin{array}{c}\text { Mean Size } \\
{[\mathrm{mm}]}\end{array}$ & $\begin{array}{c}\text { Uniformity } \\
\text { coefficient }\end{array}$ & $\begin{array}{c}\text { Specific } \\
\text { gravity }\end{array}$ & $\begin{array}{c}\text { Max } \\
\text { void } \\
\text { ratio }\end{array}$ & $\begin{array}{c}\text { Min } \\
\text { void } \\
\text { ratio }\end{array}$ & $\begin{array}{c}\text { Intern. } \\
\text { angle }\left(^{\circ}\right.\end{array}$ \\
\hline Quartzic & $0.3-0.35$ & 2 & 2.65 & 1 & 0.656 & 32 \\
\hline
\end{tabular}

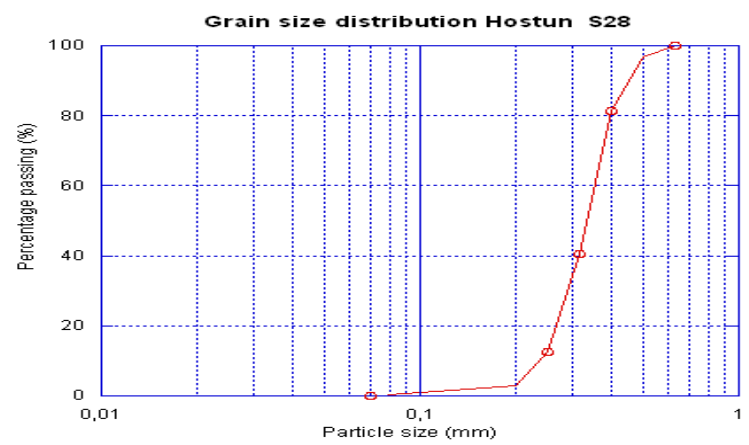

Figure 1: Hostun fine sand grain size distribution.

\section{Validation of the experimental setup}

The results obtained for load-controlled tests are compared with those obtained by Matiotti et al. [12] and by Doanh et al. [6] for displacement-controlled tests . At peak of stress,it is noted that (see Fig. 2) $\left(\eta=q / p^{\prime}=0.6\right.$ which corresponds to a mobilized angle of friction of approximately $16^{\circ}$ ). Next, results obtained for displacement-controlled tests are compared to those obtained on same sand with a very close density by Desrues and Georgopoulos [4]. The experimental device used in their study is a displacement-controlled apparatus which was modified to permit application of a constant force corresponding to peak shear stress. The constant force results from a spring attached to the displacement controlled device and the force is therefore proportional to the spring stiffness. Good agreement is shown in this figure and these results validate both the experimental device and also the sample preparation (see table 1). 


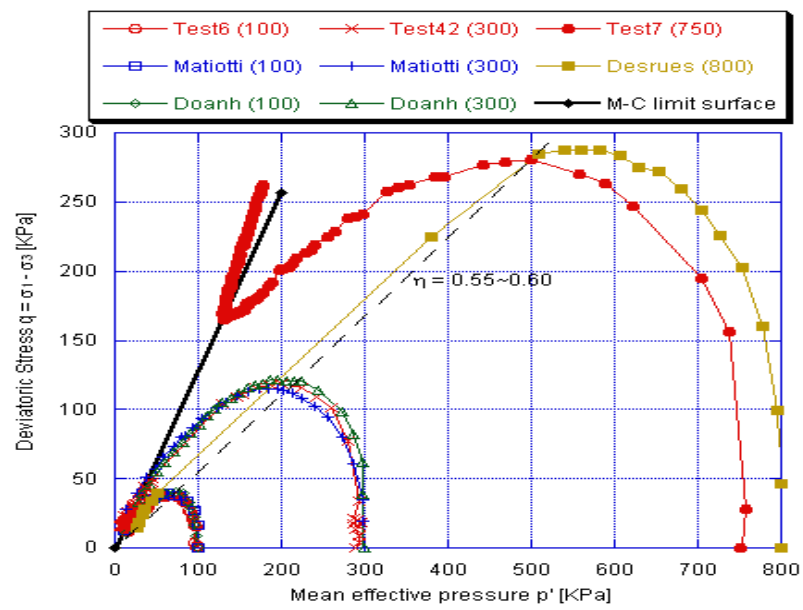

Figure 2: Comparison of our results with those of Matiotti et al. [12], Doanh et al. [6] and of Desrues and Georgopoulos [4] for $p_{o}^{\prime}=100,300,750 \mathrm{KPa}$.

\section{Constant shear stress undrained test (C.S.U.)}

An original test is presented in this section. The practical applications of this test correspond to the construction of a structure in undrained conditions on a loose sand when boundary conditions prevent the drainage (retaining walls without drainage for example). It should be noticed that these tests also correspond to those obtained for denser sands containing 5 or $10 \%$ (by mass) of fines (clayey sand for example). Practical application examples for such studies include the analysis of landslides and deep foundations.

\subsection{Constant shear stress undrained testing procedure of the}

In these tests, the isotropically consolidated samples (point A in Fig. 3) are submitted to either displacement- or stress-controlled loading (point B). It important to emphasize that the nature of these tests render it difficult to maintain constant shear stress. Indeed, a similar reduction in shear stress is noted in tests conducted by Lade [10] on closure of the drainage valve which corresponds to the undrained phase of the test. Undrained conditions are maintained and the sample is then sheared along a constant deviator stress path by decreasing the total axial stress $\left(\sigma_{1}\right)$ and the total radial stresses $\left(\sigma_{3}\right)$ from point $\mathrm{C}$ to point $\mathrm{D}$ for which an increase of the axial deformation is noticed (Fig. 5). The deviatoric stress is maintained constant up to the point E. Nevertheless, at this point, it is no longer possible to maintain the constant shear stress as on CE. Indeed, it decreases continuously, the test becomes non-controllable as defined by Nova [13]. 


\subsection{Experimental results}

Fig. 3a shows the results of a constant deviatoric undrained test on an isotropic consolidated sample $\left(p_{0}^{\prime}=\left(\sigma_{1}^{\prime}+2 \sigma_{3}^{\prime}\right) / 3=750 \mathrm{KPa}\right)$ with a void ratio before isotropic consolidation of $e_{0}=1.136$. The deviatoric stress - effective mean pressure response is shown in this figure. After undrained loading, the deviatoric stress ( $q=\sigma_{1}-\sigma_{3}$ ) was maintained approximatively constant up to $157.5 \mathrm{KPa}$ which corresponds to an anisotropic stress state $q / p^{\prime}=0.210$. To study the influence of the effective mean normal pressure, we present in Fig. $3 \mathrm{~b}$ the results obtained for $p_{0}^{\prime}=100,300$ and $750 \mathrm{KPa}$ as well as, in Fig. 4, the results obtained for two tests carried out with the same effective mean normal pressure of $300 \mathrm{KPa}$ but for two values of constant deviatoric stresses. Finally, Fig. 5 presents the deviatoric stress and the excess pore pressure versus time, the axial deformation versus time as well as the second order work versus time which is defined in section 5.2.
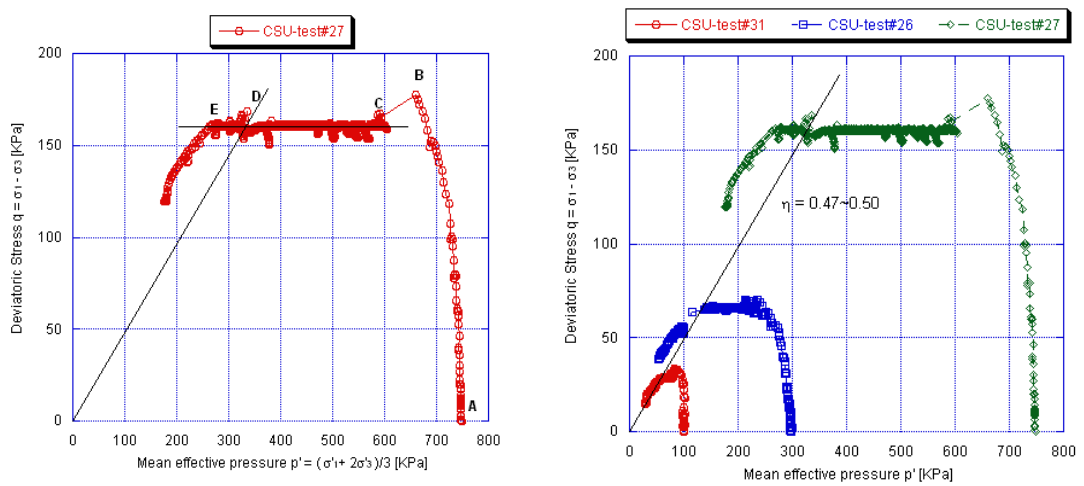

Figure 3: Constant shear undrained test: a) $\left.p_{o}^{\prime}=750 \mathrm{KPa}, \mathrm{b}\right) p_{o}^{\prime}=100,300$, $750 \mathrm{KPa}$.

\section{Results and discussion}

\subsection{Diffuse mode of failure}

The deformation of all the samples seems to be homogeneous even for large strains (after collapse): we do not notice any strain localization neither by a single shear band nor by shear bands pattern. We note on the Fig. 3 that, between the points $\mathrm{C}$ and $\mathrm{D}$, pore pressure monotonically decreases after the application of constant shear stress. This behavior is explained by the fact that the material would tend to dilate if it had the ability (isotropic unloading) but the isochoric condition is imposed. Moreover, the analysis of pore pressure variation at the time of collapse highlights two points: 


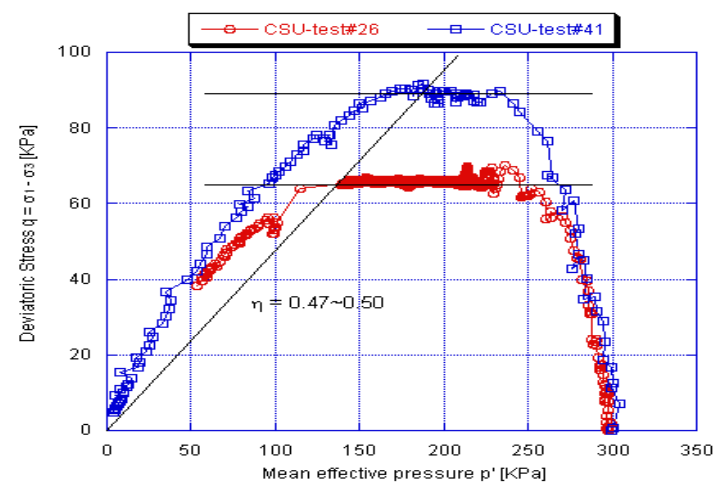

Figure 4: Constant shear undrained test: $p_{o}^{\prime}=300 \mathrm{KPa} q=65.26$ and $91.55 \mathrm{KPa}$.

- Collapse occurs while the pore pressure decreases meaning that the increase in pore pressure is related to collapse even in undrained conditions like showed by Eckerley [7] for drained conditions (Fig. 5). Therefore, pore pressure is not a trigger parameter for collapse.

- The increase in the pore pressure during collapse is more than likely the result of a diffuse mode of deformation rather than a localized one since, upon localized deformation, no notable change in pore pressure should be observed.

\subsection{Characteristic of the constant shear undrained test}

The sign of the second order work, based on the local condition of stability defined by Hill [9], can be used to study the stability of the tested material. In axisymmetric conditions, the second order work is defined ([2], [3], [15]):

$$
d^{2} W=d \sigma_{i j} d \varepsilon_{i j}=d \sigma_{1} d \varepsilon_{1}+2 d \sigma_{3} d \varepsilon_{3}>0
$$

which can be re-arranged to give:

$$
d^{2} W=d q d \varepsilon_{1}+d \sigma_{3} d \varepsilon_{v}
$$

with $d q=d \sigma_{1}-d \sigma_{3}$ et $d \varepsilon_{v}=d \varepsilon_{1}+2 d \varepsilon_{3}$

As it is not possible to impose both conditions (isochoric condition and $q=c s t$ ) which implies that $d^{2} W=0$ we impose $d \varepsilon_{v}=0$ and $d q= \pm k$, where $k$ depends on the test $(0.5$ or $1 \mathrm{KPa})$. Fig. 5 illustrates that, the second order work is negative when collapse occurs.

Sometimes, for the same density, sample collapse inside the unstable domain but before reaching the stress state $\eta=0.47-0.50$. This behavior can be explained by an imperfection of the experimental device or by a disturbance in the loading. 
This observation is important for the study of slope instability because such disturbances can occur that lead to failure on slopes smaller than $10^{\circ}$ and it can be considered as trigger factors.

\section{Conclusions}

In this work, we set up a device allowing to test samples of soils by applying either a displacement-controlled or a load-controlled test. The device is validated by comparing results for both loading paths and also through comparison them with results obtained by other authors on same materials under similar conditions. A constant shear stress undrained test (C.S.U.) was applied to this material. The results obtained are presented and discussed. Analysis of pore pressure evolution highlights a diffuse mode of deformation during collapse. Moreover, the break in the pore pressure evolution slope makes it possible, during the test, to locate the

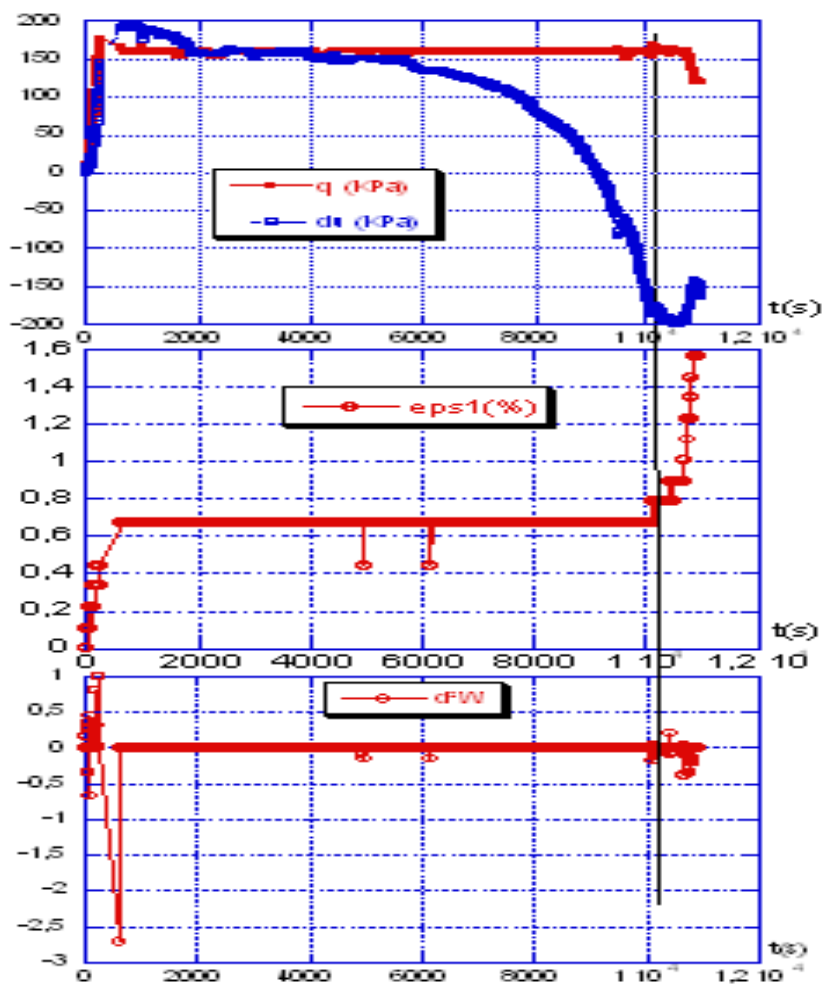

Figure 5: Constant shear undrained test $\left(p_{o}^{\prime}=750 \mathrm{KPa}\right)$ : deviatoric and excess pore pressure versus time, axial displacement versus time and second order work versus time. 
moment when collapse occurs. The increase in the pore pressure is thus the consequence of collapse and not a triggering factor. Second order work calculated from the experimental results becomes negative at the time of collapse. We also noted that, on certain tests, collapse can occur, inside the bifurcation domain, in any point during the constant stress shear undrained test. Indeed, along this particular stress path, a disturbance or an imperfection of the experimental device can cause collapse. From a practical point of view, these disturbances, that need further investigations, can be shown as trigger factors of instability. One should notice that this collapse always occurs strictly inside the Mohr-Coulomb limit surface of plasticity and that explain certain ruptures which can not be explained by the classical theory of plasticity.

\section{References}

[1] Chu J. and Leong W.K. Effect of fines on instability behaviour of loose sand. Geotechnique, 52(10):751-755, 2002.

[2] Darve F. and Laouafa F. Instabilities in granular materials and application to landslides. Mech. Cohes. Frict. Mater., 5(8):627-652, 2000.

[3] Darve F., Servant G., Laouafa F., and Khoa H.D.V. Failure in geomaterials: continuous and discrete analyses. Comp. Methods Appl. Mech. Engrg, 193:3057-3085, 2004.

[4] Desrues J. and Georgopoulos I.O. To be published. Soils and Foundations, 2005.

[5] di Prisco C. and Imposimato S. Experimental analysis and theoretical interpretation of triaxial load controlled loose sand specimen collapses. Mech. Cohes. Frict. Mater., 2:93-120, 1997.

[6] Doanh T., Ibraim E., and Matiotti R. Undrained instability of very loose hostun sand in triaxial compression and extension. part 1: experimental observations. Mech. Cohes. Frict. Mater., 2:47-70, 1997.

[7] Eckersley J.D. Instrumented laboratory flowslides. Geotechnique, 40(3):489-502, 1990.

[8] Gajo A. The influence of system compliance on collapse of triaxial sand samples. Can. Geotech. J., 41:257-273, 2004.

[9] Hill R. A general theory of uniqueness and stability in elastic-plastic solids. J. Mech. Phys. Solids, 6:239-249, 1958.

[10] Lade P.V. Instability, shear banding, and failure in granular materials. Int. J. of Solids and Structures, 39:3337-3357, 2002.

[11] Laouafa F. and Darve F. Modelling of slope failure by a material instability mechanism. Comp. Geotechn, 29:301-325, 2001.

[12] Matiotti R. and di Prisco C., and Nova R. Experimental observations on static liquefaction of loose sand. In Earthquake Geotechnical Engineering, Ishihara editions, Balkema, pages 817-822, 1995.

[13] Nova R. Controllability of the incremental response of soil specimens subjected to arbitrary loading programmes. J. Mech. behav. Mater., 5, N²:193201, 1994. 
282 Monitoring, Simulation, Prevention and Remediation of Dense and Debris Flows

[14] Skopek P.and Morgenstern N.R. and Robertson P.K. and Sego D.C. Collapse of dry sand. Can. Ceotech. J., 31:1008-1014, 1994.

[15] Servant G., Darve F., Desrues J., and Georgopoulos I.O. Diffuse modes of failure in geomaterials. In Di Benedetto, editor, Deformation characteristics of geomaterials. Swets \& Zeitlinger, pages 181-198, 2005. 